\title{
Serum malondialdehyde concentration in babies with hyperbilirubinaemia
}

\author{
Šule Yiğit, Murat Yurdakök, Kamer Kilinç, Olcay Oran, Gülsen Erdem, Gülsevin Tekinalp
}

\begin{abstract}
Aim-To determine lipid peroxide concentrations in the first $\mathbf{1 0}$ days of life. Methods-Malondialdehyde concentrations were investigated in neonates with or without hyperbilirubinaemia during the first 10 days of life.

Results-Serum malondialdehyde concentrations were higher in infants with hyperbilirubinaemia than in controls. A positive correlation was found between malondialdehyde and bilirubin concentrations in the study group. When the study group was categorised according to the presence of haemolysis, a significant correlation was found between malondialdehyde and bilirubin concentrations in those infants with hyperbilirubinaemia due to haemolysis. There was no such correlation in those without haemolysis. Conclusion-Exchange transfusion rapidly produces variable changes in prooxidant and antioxidant plasma concentrations in neonates, which may be responsible for free radical metabolism. The fall in malondialdehyde concentration is probably directly related to its exogenous removal by exchange transfusion. (Arch Dis Child Fetal Neonatal Ed 1999;80:F235-F237)
\end{abstract}

Keywords: bilirubin; oxygen free radicals; malondialdehyde

Free radical reactions are part of many biological processes. Molecular oxygen, present in all aerobic organisms, readily accepts an electron, resulting in the formation of oxygen free radicals. ${ }^{1}$ These are implicated in many disease processes, including pulmonary oxygen injury, intraventricular haemorrhage, retinopathy of prematurity, ischaemia/reperfusion injury manifest as necrotising enterocolitis, postasphyxial central nervous system injury, and acute tubular necrosis. ${ }^{1-3}$

The body defends itself against the toxicity of oxygen free radicals using enzymatic mechanisms - superoxide dismutases, catalase, glutathione peroxidase-as well as non-enzymatic ones-several antioxidant vitamins. $^{4-6}$ Furthermore, a series of compounds and metabolites such as mannitol, uric acid, bilirubin and many others act as oxygen radical scavengers. ${ }^{58}$ Bilirubin is generally regarded as a toxic compound and it is responsible for the development of kernicterus. However, the bile pigments bilirubin and biliverdin also protect cellular membrane lipids from oxidative destruction. ${ }^{7-9}$ Bilirubin is an efficient scavenger of reactive oxygen species and its increase could be a response to initial oxidative stress. ${ }^{1}$ Malondialdehyde, which is a highly reactive metabolite of free radical induced lipid peroxide ${ }^{10}$ is a commonly used index of lipid peroxide. ${ }^{11-13} \mathrm{We}$ therefore studied malondialdehyde concentrations in newborn infants with or without hyperbilirubinaemia to determine lipid peroxide concentrations.

\section{Methods}

The study group comprised 58 term newborn infants admitted to Hacettepe University Hospital because of clinically significant indirect hyperbilirubinaemia. Infants with severe congenital malformation, sepsis, or birth asphyxia were excluded from the study. Clinically significant indirect hyperbilirubinaemia was defined as being present in infants with a serum total bilirubin concentration of more than 12.8 $\mathrm{mg} / \mathrm{dl}^{14}$

The study group was divided into groups according to the aetiology of hyperbilirubinaemia: 19 of the 58 infants (group I) had haemolytic type hyperbilirubinaemia due to blood group ( $\mathrm{Rh}$ or $\mathrm{ABO}$ ) incompatibility. However, no aetiological factor for hyperbilirubinaemia could be found for the other 39 babies (group II). ABO incompatibility was diagnosed if visible jaundice began in the first 24 hours of life, with the presence of spherocytosis in peripheral blood smears in type A or B infants born to type $\mathrm{O}$ mothers. ${ }^{15}{ }^{16} \mathrm{Rh}$ incompatibility was diagnosed if the direct antiglobulin test was positive in $\mathrm{Rh}$ positive babies born to mothers who were blood type Rh negative..$^{15} 16$ The control group consisted of 24 healthy term infants 2 to 10 days old without visible jaundice.

Blood samples were taken from a peripheral vein to determine malondialdehyde concentrations on the first day of admission. Bilirubin concentrations were also determined at the same time.

Exchange transfusion was performed on 31 infants whose bilirubin concentrations were above the determined values, depending on birthweight and gestational age. ${ }^{15}$ Second blood samples were taken from the 31 infants (nine from group I, 22 from group II) at the end of exchange transfusion. Blood samples were centrifuged at $3000 \mathrm{rpm}$ for 3 minutes within 15 minutes of collection. Serum samples were stored at $-20^{\circ} \mathrm{C}$ and analysed within two months. The concentrations of lipid peroxides in serum was measured using the thiobarbituric acid (TBA) test, as described by Wade and van $\mathrm{Rij} .{ }^{17}$ Although the reactivity of TBA is not only limited to malondialdehyde, this method is one of the most commonly used for detecting oxidative modification of lipids, and hence oxidative stress. For detecting TBA reacting substances (TBARS) $0.2 \mathrm{ml}$ of trichloroacetic acid (TCA, $25 \mathrm{~g}$ TCA in $10 \mathrm{ml}$ 
Table 1 Characteristics of infants with or without hyperbilirubinaemia (mean [SD] (range))

\begin{tabular}{lll}
\hline & $\begin{array}{l}\text { Hyperbilirubinaemia } \\
(n=58)\end{array}$ & Controls $(n=24)$ \\
\hline Male/female & $34 / 24$ & $14 / 10$ \\
Gestational age (weeks) & $38.9[1.1](38-40)$ & $38.6[0.8](38-40)$ \\
Birthweight (g) & $3031[454](2040-4040)$ & $3177[254](2800-4150)$ \\
Apgar score $(5$ mins) & $9.6[0.7](8-10)$ & $9.8[0.5](9-10)$ \\
Day of sample collection & $5.1[2.8](1-10)$ & $4.4[1.6](2-10)$ \\
Serum bilirubin (mg/dl) & $23.9[5.7](15-48)$ & - \\
Serum malondialdehyde $(\mu \mathrm{mol} / \mathrm{l})$ & $9.1[4.2]^{\star}(2.5-22.5)$ & $5.2[1.3]^{\star}(3.8-10.5)$ \\
\hline
\end{tabular}

${ }^{\star} \mathrm{p}<0.001$

Table 2 Characteristics of hyperbilirubinaemic infants with or without haemolysis (Mean [SD] (range))

\begin{tabular}{lll}
\hline & $\begin{array}{l}\text { Group I infants with } \\
\text { haemolysis }(n=19)\end{array}$ & $\begin{array}{l}\text { Group II infants without } \\
\text { haemolysis }(n=39)\end{array}$ \\
\hline Male/female & $13 / 6$ & $21 / 18$ \\
Gestational age (weeks) & $39.1[1.1](38-40)$ & $38.9[1.1](38-40)$ \\
Birthweight $(\mathrm{g})$ & $3007[510](2040-3800)$ & $3044[446](2230-4040)$ \\
Serum bilirubin $(\mathrm{mg} / \mathrm{dl})$ & $24.8[7.7](15-48)$ & $23.5[4.5](17-43)$ \\
Serum malondialdehyde $(\mu \mathrm{mol} / \mathrm{l})$ & $9.4[4.7](4.9-22.5)$ & $8.9[4.3](2.5-20.9)$ \\
\hline
\end{tabular}

${ }^{\star} \mathrm{p}>0.05$.

distilled water) was added to $1 \mathrm{ml}$ serum by vigorous shaking. After centrifugation at 1000 $\times g$ for 10 minutes, the supernatant fluid was neutralised with $4 \mathrm{M} \mathrm{NaOH}$. Neutralised supernatant $(1 \mathrm{ml})$ was reacted with $1 \mathrm{ml}$ TBA $(0.67 \%)$ and the mixture was then heated at $100^{\circ} \mathrm{C}$ for 30 minutes. The absorption of cooled samples was measured at $532 \mathrm{~nm}$. Tetramethoxy propane was used as standard. Malondialdehyde concentrations (measured as TBARS) were calculated as $\mu \mathrm{mol} / 1$.

Data are presented as means (SD). Differences among groups were tested using Student's $t$ test and $\chi^{2}$ analysis. Correlation analysis was used to determine the relation between variables.

\section{Results}

Study and control groups were similar for sex, gestational age, birthweight, Apgar scores,

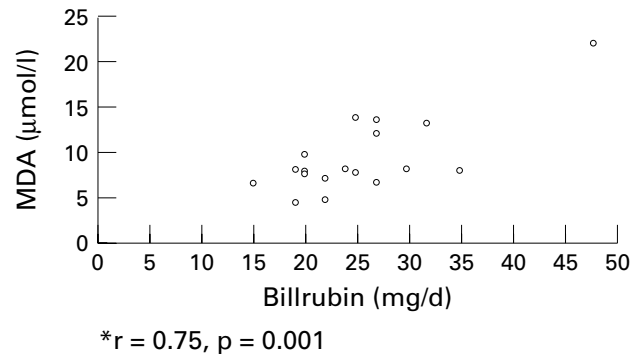

Figure 1 Correlations between malondialdehyde and bilirubin concentrations in study group.

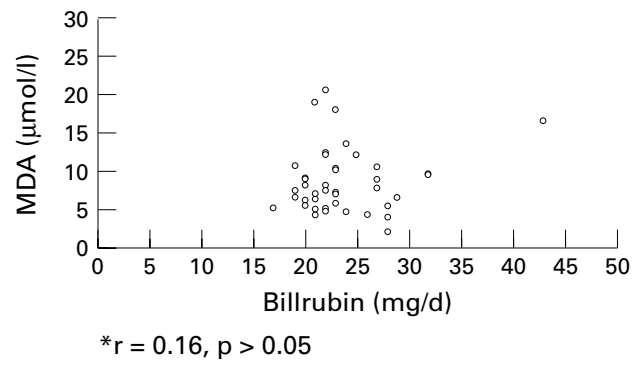

Figure 2 Correlation between malondialdehyde and bilirubin concentrations in group 1. maternal age and the day of blood sample collection (table 1).

The mean serum malondialdehyde concentration was higher in the study group than in the control group $(\mathrm{p}<0.001)$ (table 1$)$ and a positive correlation was found between malondialdehyde and bilirubin concentrations in the study group $(r=0.40, p=0.01)$. There was no correlation between malondialdehyde concentration and gestational age, birthweight, and day of sample collection.

Although serum malondialdehyde concentration was slightly higher in the infants with haemolysis (group I), there was no significant difference between the groups $(p>0.05)$ (table 2). A significant positive correlation was found between serum malondialdehyde and bilirubin concentrations in group $\mathrm{I}(\mathrm{r}=0.75, \mathrm{p}=0.00)$ (fig 1). However, there was no such correlation in the infants without haemolysis (group II) $(\mathrm{r}=0.16, \mathrm{p}>0.05)$ (fig 2).

There was a significant decrease in the serum concentrations of bilirubin and malondialdehyde after exchange transfusion. No correlation between the two was found after exchange transfusion in these infants.

\section{Discussion}

Bilirubin is generally regarded as a toxic compound when, in its unconjugated form, it accumulates to abnormally high concentrations in biological tissues, and is thus responsible for the development of kernicterus. ${ }^{15}{ }^{18}$ However, bilirubin also functions as a natural antioxidant. Bilirubin reactions involving free radicals or toxic oxygen reduction products have been well documented: unconjugated bilirubin scavenges singlet oxygen with high efficiency, reacts with superoxide anions and peroxyl radicals, and serves as a reducing substrate for peroxidases in the presence of hydrogen peroxide or organic hydroperoxides. ${ }^{78}$ Albumin bound bilirubin efficiently inhibits the peroxyl radical induced oxidation of fatty acids. ${ }^{9}$ In the intestine, conjugated bilirubin also serves as a natural antioxidant which protects oxidisable substances from destruction in the intestinal tract. $^{8}$

Bilirubin is important as an antioxidant as its concentration is thought to increase in response to oxidative stress. ${ }^{1}$ Haem oxygenase (HO) is a microsomal enzyme that catalyses the degradation of haem to biliverdin, and then by activation of biliverdin reductase, to bilirubin. Oxidation of haem is carried out by two isoenzymes of the microsomal $\mathrm{HO}, \mathrm{HO}-1$ and $\mathrm{HO}-2$. HO-1 is the commonly known $\mathrm{HO}$, the activity of which can be increased up to 100 -fold in response to a wide variety of stimuli (metals, haem, hormones, etc) ${ }^{19}$ Therefore, HO-1 has also been classified as a heat shock protein. HO-2, the major isoform present under physiological conditions, was only recently discovered and this isoenzyme seems to be uninducible..$^{19}{ }^{20}$ It has been shown that in rat liver, cobalt chloride $\left(\mathrm{CoCl}_{2}\right)$ injections decreased the activity of antioxidant enzymes like superoxide dismutase, catalase, and glutathione peroxidase, suggesting that $\mathrm{CoCl}_{2}$ is a trigger for oxidative stress. ${ }^{21}$ After $\mathrm{CoCl}_{2}$ injection, $\mathrm{HO}$ activity was found to have increased. 
However, this increase in haem oxygenase activity was prevented by administration of bilirubin. ${ }^{21}$ Thus an increase in bilirubin as a result of $\mathrm{HO}$ induction could be a response to the initial oxidative stress. ${ }^{21}{ }^{22}$ As bilirubin is a potent antioxidant and haem is a pro-oxidant, the increase in $\mathrm{HO}$ activity has been implicated in tissue protection against oxidative stress.

In our study, malondialdehyde concentration was significantly higher in infants with hyperbilirubinaemia, indicating that the bilirubin increase may be a response to oxidative stress in these patients. The causes of hyperbilirubinaemia in babies can be classified into two groups: haemolytic and non-haemolytic. Therefore this investigation was planned to further evaluate the correlation between malondialdehyde and bilirubin, this time in relation to the aetiology of hyperbilirubinaemia. As all infants in this study were in the first 10 days of life all were being breastfed. So feeding mode was not a factor for nonhaemolytic jaundice.

While our study clearly establishes a correlation between malondialdehyde and bilirubin concentrations in jaundiced infants, the two categories in the study group did not show the same degree of correlation. Those infants with hyperbilirubinaemia and haemolysis had a high level of correlation between malondialdehyde and bilirubin concentrations. On the other hand, those without haemolysis did not show any significant correlation between concentrations of bilirubin and malondialdehyde, both of which were high.

The clear correlation in the group with haemolysis may be explained by its effect on oxidative stress and bilirubin production. Haemolysis itself leads to an increase in oxidative stress. ${ }^{23-25}$ Haemolysis also leads to an increase in bilirubin concentration. As increased haemolysis causes increased oxidative stress, it seems that bilirubin, a product of the haemolytic process, may protect against the potential deleterious effects of that process. This may explain why haem is excreted as bilirubin rather than as biliverdin. This may be the reason for the positive correlation found between malondialdehyde and bilirubin concentrations in patients with haemolysis.

The situation of infants without haemolysis is less obvious. In this category the increase in bilirubin concentrations cannot be accounted for by factors such as haemolysis. Therefore, the rise in bilirubin may be a response to oxidative stress in this group. ${ }^{21}{ }^{24}$ However, in this case, the absence of apparent correlation between the high concentrations of bilirubin and malondialdehyde may be indicative of a more complex interaction between them. Such an interaction could explain why bilirubin toxicity is rare in term babies without haemolysis. Perhaps hyperbilirubinaemia, which is often seen in neonates, has a role in the defence mechanisms when antioxidant mechanisms are not yet fully developed.

Exchange transfusion rapidly produced variable changes in the concentrations of prooxidant and antioxidant substances in plasma and may thus influence free radical metabolism in neonates. ${ }^{26}$ There was a significant decrease in the concentrations of bilirubin and malondialdehyde after exchange transfusion. The fall in malondialdehyde concentration was probably directly related to its exogenous removal by the exchange transfusion.

1 Saugstad OD. Free radicals in neonatal intensive care. In: Týbboel D, Van der Voort E, eds. Intensive care in childhood: A challenge to the future, update in intensive care and emergency A challenge to the future, update in intensive ca

2 Warner BB, Wispe JR. Free radical mediated diseases in pediatrics. Semin Perinatol 1992;16:47-57.

3 Cheeseman KH, Slater TF. An introduction to free radical biochemistry. Br Med Bull 1993;49:481-93.

4 McCord JM, Keele BB, Fridowich I. An enzyme based theory of obligate anaerobiosis: The physiological function theory of obligate anaerobiosis: The physiological function of superoxide

5 Stocker R, Frei B. Endogenous antioxidant defences in human blood plasma. In: Sies H, ed. Oxidative Stress: Oxidants and Antioxidants. London: Academic Press, 1991: 213-42.

6 Ýnan Ç, Kýlýç Ý, Kýlýnç K, Kalaycý Ö, Kotiloğlu E. The effect of high dose antenatal vitamin $\mathrm{E}$ on hypoxia induced changes in newborn rats. Pediatr Res 1995;38:685-9.

7 Stocker R, Yamamoto Y, McDonagh AF, Glazer AN, Ames $\mathrm{BN}$. Bilirubin is an antioxidant of possible physiological importance. Science 1987;235:1043-6.

8 Stocker R, Ames BN. Potential role of conjugated bilirubin and copper in the metabolism of lipid peroxides in bile. Proc Natl Acad Sci USA 1987;84:8130-4.

9 Stocker R, Glazer AN, Ames BN. Antioxidant activity of albumin bound bilirubin. Proc Natl Acad Sci USA 1987;84:5918-922.

10 Esterbauer H, Schaur RJ, Zollner H. Chemistry and biochemistry of 4-hydroxynonenal, malonaldehyde and related aldehydes. Free Rad Biol Med 1991;11:81-128.

11 Inder TE, Graham P, Sanderson K, Taylor BJ. Lipid peroxidation as a measure of oxygen free radical damage in the very low birthweight infant. Arch Dis Child 1994;70:F107F11.

12 Schlenzig JS, Bervoets K, Loewenich VV, Böhles H. Urinary malondialdehyde concentration in preterm neonates: is there a relationship to disease entities of neonatal intensive care ? Acta Paediatr 1993;82:202-5.

13 Inder TE, Darlow BA, Sluis KB, et al. The correlation of elevated levels of an index of lipid peroxidation (MDATBA) with adverse outcome in the very low birth weight infant. Acta Paediatr 1996;85:1116-22.

14 Newman TB, Maisels MJ. Evaluation and treatment of jaundice in the term newborn: A kinder, gentler approach. Pediatrics 1992;89:809-18.

15 Maisels MJ. Jaundice. In: Avery GB, Fletcher MA, Macdonald MG, eds. Neonatology. Phiadelphia: JB Lippincott, 1994: 630-725.

16 Balanchette V, Doyle J, Schmidt B, Zipursky A. Hematology. In: Avery GB, Fletcher MA, Macdonald MG, eds Neonatology. Phiadelphia: JB Lippincott, 1994: 952-99.

17 Wade CR, van Rij AM. Plasma thiobarbituric acid reactivity: Reaction conditions and the role of iron, antioxidants and lipid peroxy radicals on the quantitation of plasma lipid peroxides. Life Sci 1988;43:1085-93.

18 Hansen TW, Poulsen JP, Bratlid D. The effects of hypoxantine, xantine oxidase and hyperoxia on the accumulation of
bilirubin and albumin in young rat brain. Early Hum Dev 1992;30:171-7.

19 Willis D, Moore AR, Frederick R, Willoughby DA. Heme oxygenase : a novel target for the modulation of the inflammatory response. Nat Med 1996;2:87-90.

20 Maines MD. Heme oxygenase : function, multiplicity, regulatory mechanism, and clinical applications. FASEB $\mathcal{F}$ 1988;2:2557-68.

21 Llesuy SF, Tomaro ML. Heme oxygenase and oxidative stress. Evidence of involvement of bilirubin as physiological protector against oxidative damage. Biochim Biophys Acta 1994;1223:9-14.

22 Ossola JO, Tomaro ML. Heme oxygenase induction by cadmium chloride: evidence for oxidative stress involvement. Toxicology 1995;104:141-7.

23 Phylactos AC, Leaf AA, Costeloe K, Crawford MA. Erythrocyte cupric/zinc superoxide dismutase exhibits reduced activity in preterm and low birthweight infants at birth. Acta Paediatr 1995;84:1421-5.

24 Sullivan JL. Iron, plasma antioxidants, and the 'oxygen radical disease of prematurity. Am f Dis Child 1988;142:1341-4.

25 Cooke RWI, Clark D, Hickey-Dwyer M, Weindling AM. The apparent role of blood transfusions in the development of retinopathy of prematurity. Eur $\mathcal{f}$ Pediatr 1993;152:833-6.

26 Lindeman JHN, Lentjes EGWM, Houdkamp E, ZoerenGrobben D, Schrijver J, Berger HM. Effect of an exchange transfusion on plasma antioxidants in the newborn. Pediatrics 1992;90:200-3. 